\title{
Seasonal differences in cytokine expression in the skin of Shetland ponies suffering from insect bite hypersensitivity.
}

\author{
C. Meulenbroeks ${ }^{a}$, N.M.A. van der Meide ${ }^{\text {b }}$, D.M.W. Zaiss ${ }^{a}$, M.M. Sloet van
} Oldruitenborgh-Oosterbaan ${ }^{c}$, J.J. van der Lugt ${ }^{d}$, J. Smak ${ }^{\text {, }}$, V.P.M.G. Rutten ${ }^{\mathrm{a}, \mathrm{f}}$, T. Willemse $^{\mathrm{a}, \mathrm{g}}$

\footnotetext{
${ }^{a}$ Department of Infectious Diseases and Immunology, Faculty of Veterinary Medicine, Utrecht University, Utrecht, The Netherlands

${ }^{\mathrm{b}}$ Department of Cell Biology \& Immunology, Wageningen University, Wageningen, The Netherlands

c Department of Equine Sciences, Faculty of Veterinary Medicine, Utrecht University, Utrecht, The Netherlands

${ }^{d}$ Vet Med Lab, IDEXX laboratories, Hoofddorp, The Netherlands

e De Graafschap Dierenartsen, Vorden, The Netherlands

${ }^{f}$ Department of Veterinary Tropical Diseases, Faculty of Veterinary Science, University of Pretoria, Pretoria, Onderstepoort South Africa

${ }^{g}$ Department of Clinical Sciences of Companion Animals, Faculty of Veterinary Medicine, Utrecht University, Utrecht, The Netherlands
}

Corresponding author: Chantal Meulenbroeks Tel.: +31 30253 5836; Fax: +31 30253 3555; E-mail address: c.meulenbroeks@uu.nl

Correspondence address: Chantal Meulenbroeks, Department of Infectious Diseases and Immunology, Yalelaan 1, 3584 CL Utrecht; The Netherlands; c.meulenbroeks@uu.nl

\begin{abstract}
Insect bite hypersensitivity (IBH) in horses is a seasonal, IgE-mediated, pruritic skin disorder primarily caused by Culicoides spp.

We hypothesize that a mixed Th2/Th1-type immune status, off season, alters into Th2-dominated immune reactivity in the skin of IBH-affected ponies in the IBH season.
\end{abstract}


To study these immune response patterns Culicoides-specific IgE levels, skin histopathology and cytokine and transcription factor mRNA expression (IL4, IL10, IL13, IFNY, FoxP3 and $\mathrm{CD}_{\zeta}$ ) in lesional and non-lesional skin of ponies affected by IBH in the IBH season were compared with those of the same animals off season and those in skin of healthy ponies in both seasons.

The present study revealed a significantly higher histopathology score in lesional skin of affected ponies than in non-lesional skin and skin of healthy ponies in the IBH season. C. obsoletus-specific IgE serum levels of ponies with IBH were significantly higher than those in healthy ponies in both seasons. Interestingly, C. obsoletus-specific IgE serum levels within each group were the same in the IBH season and off season. The expression of IL4, IL13 and IFNY mRNA in skin biopsies in the IBH season showed a significant increase compared to off season in both skin derived from healthy control ponies $(n=14)$ as well as in lesional and in non-lesional skin from IBH-affected animals $(n=17)$. This apparently general up-regulation of cytokine expression during the IBH season directly correlated with an increased $C D 3 \zeta$ mRNA expression in the skin, indicating an overall increased $\mathrm{T}$ cell influx during the summer months. The only significant difference observed between lesional skin from IBH-affected animals as compared to skin from healthy control animals in the IBH season was a lower expression of IL13/CD3 $\zeta$ in the affected animals. FoxP3 and IL10 levels were unaffected, except for a lower expression of FoxP3 in healthy control skin in the IBH season as compared to off season, In addition, the increased level of $C$. obsoletus-specific IgE did not correlate with higher histological scores in LE skin. In summary, our data indicate a general immune activation in the skin of both healthy and IBH-affected ponies during the IBH season that potentially obscures the Culicoides-specific immune reaction pattern, even in lesional skin of IBHaffected animals. 
Keywords: insect bite hypersensitivity (IBH), Culicoides spp., horse, IgE, cytokines, transcription factors, Th1/Th2

\begin{tabular}{ll}
\multicolumn{2}{l}{ Abbreviations: } \\
CDNA & complementary Deoxyribonucleic Acid \\
C. obsoletus & Culicoides obsoletus \\
Co & Control \\
FAD & Flea allergy dermatitis \\
HE & Haematoxylin-eosin \\
IBH & Insect bite hypersensitivity \\
LE & Lesional \\
mRNA & messenger Ribonucleic Acid \\
NL & Non-lesional \\
qRT-PCR & quantitative real time PCR \\
RNA & Ribonucleic acid \\
WBE & Whole body extract
\end{tabular}

\section{Introduction}

Equine insect bite hypersensitivity (IBH) is a seasonally recurrent, pruritic skin disorder mainly caused by the bites of female Culicoides spp. (Anderson et al., 1988, van der Rijt et al., 2007, Van Grevenhof et al., 2007, de Raat et al., 2008, van den Boom et al., 2008). In Europe all horses are exposed to Culicoides bites and develop IgG antibodies to salivary antigens. About 5 percent of horses develop clinical signs of allergy with elevated Culicoides-specific IgE (Hellberg et al, 2006; Wilson et al, 2001; Wagner et al, 2006). Approximately 95 percent of the Culicoides spp. found around IBH horses in the Netherlands and other European countries, such as Sweden is C. obsoletus (van der Rijt et al., 2007, de Raat et al., 2008, Ander et al., 2012). Clinically, at onset IBH is characterized by 
intense pruritus with papules and wheals, which develop into serous crusts, scaling and alopecia on the mane, tail and in some cases the ventral midline, when the disease becomes chronic (Steinman et al., 2003, Ferroglio et al., 2006, Kolm et al., 2007). Lesions are only observed during the Culicoides season and are absent off season. The diagnosis of IBH is based on these characteristic seasonal clinical manifestations as well as skin test reactivity to the geographically relevant Culicoides antigen (Sloet van Oldruitenborgh-Oosterbaan et al., 2008). Histologically, IBH lesions are characterized by a mixed perivascular to diffuse cellular infiltrate consisting of mainly CD4+ T cells (McKelvie et al., 1999) and, especially in acute lesions, eosinophils (Scott, 1990, Kurotaki et al., 1994).

Expression levels of IL13 mRNA, but not of IL4 or IL5 mRNA, have been described to be significantly elevated in lesional and non-lesional skin of IBHaffected horses (Heimann et al, 2011). On the other hand, IL10 mRNA levels were lower in lesional compared to non-lesional skin, but this difference was not statistically significant (Heimann et al., 2011). An increase in IL4 mRNA production with a concomitant decrease in IFNY mRNA production by cultured equine PBMC was observed during the IBH season (Hamza et al., 2007, Hamza et al., 2008, Hamza et al., 2010).

No differences in total serum IgE levels were found between healthy horses and animals affected by IBH (Wagner et al., 2003). However, Culicoides-specific IgE serum titers have been reported to be higher in horses with IBH (Wilson et al., 2001, Hellberg et al., 2006, Wagner et al., 2006, Heimann et al., 2011) as compared to healthy horses. Correlations between Culicoides-specific IgE titers and histological scores for IBH have not been reported so far, nor have differences in these disease parameters between the IBH season and off season been investigated.

In order to better understand the pathogenesis of IBH we investigated the differences in skin pathology and cytokine expression between IBH "on and off" 
season. We hypothesize that the immune balanse (a mixed Th2/Th1-type) off season alters into a Th2-dominated immune response in the skin of ponies with clinical manifestations of IBH, due to exposure to $\mathrm{C}$. obsoletus. Therefore we have compared Culicoides-specific IgE serum levels, parameters of dermatopathology, the mRNA expression of cytokines (IL4, IL10, IL13, IFNY), the transcription factor FoxP3 and the $\mathrm{T}$ cell receptor linked $\mathrm{CD}_{\zeta}$ in lesional and non-lesional skin of ponies affected by IBH during the IBH season with those of the same animals off season, as well as of healthy control ponies in both seasons.

Our results show significantly higher histopathology scores in lesional skin of affected ponies than in non-lesional skin in the IBH season. The same result was observed when comparing lesional skin of IBH ponies and skin from control ponies in the IBH season. Culicoides-specific IgE serum levels were higher in IBHaffected ponies compared to control animals, but within the group of IBH-affected ponies they were equally high in each season. In addition, in both IBH skin and control skin there was an upregulation of $\mathrm{CD}_{\zeta}, \mathrm{IL} 4, \mathrm{IL} 13$ and IFNY during the IBH season compared to the situation off season. Except for a down regulation of FoxP3 in healthy control skin in the IBH season compared to off season, FoxP3 and IL10 levels were unaffected.

\section{Material and Methods}

\subsection{Animals}

A total of 31 privately-owned Shetland ponies were included in the study. Ponies with IBH ( $n=17$, age range 3-19 years) were selected on the basis of clinical symptoms and history, i.e. recurrent, seasonal, pruritic skin lesions located at the mane, tail and ventral midline with remission off season. Control ponies ( $n=14$, age range 2-20 years) were randomly chosen from the same stables as the ponies with IBH and had no clinical symptoms or history of IBH. 
Ponies in both groups were dewormed and vaccinated at regular intervals and did not receive any corticosteroid treatment.

All animal experiments were approved by the Animal Ethics Committee of the Utrecht University.

\subsection{Collection and processing of blood and skin samples}

To ensure that ponies were not exposed to Culicoides spp. recently, off season samples were taken in March 2011 before the start of the IBH season when the average maximum temperature was $11.1^{\circ} \mathrm{C}$ and midnight temperatures were down to $-2.5^{\circ} \mathrm{C}$. During the Culicoides season in August 2011 (with an average maximum temperature of $20.2^{\circ} \mathrm{C}$ ) to insure maximum exposure to Culicoides the same ponies were sampled again.

Skin biopsies of $4 \mathrm{~mm}$ were taken under local anesthesia with $2 \%$ lidocaine (B. Braun, AG Melsungen, Deutschland). Biopsies of healthy and non-lesional skin were collected from the dorsolateral neck, whereas chronic lesional skin biopsies were taken from the crest. There were no acute lesions present at the time of sampling.

Three biopsies were taken per sampling site: the first two were snap-frozen in liquid nitrogen and stored at $-70^{\circ} \mathrm{C}$ until used for RNA isolation. The third biopsy was fixed in $4 \%$ neutral buffered formaldehyde for 24-48 $\mathrm{h}$ and paraffinembedded for histopathology.

Blood samples $(20 \mathrm{ml})$ were collected from the jugular vein of each pony in off and IBH seasons into heparin tubes. Serum was separated after centrifugation and frozen at $-20^{\circ} \mathrm{C}$ until analyzed for Culicoides-specific IgE levels.

\subsection{C. obsoletus whole body extract preparation}

Whole body extract (WBE) was prepared from about three hundred female $C$. obsoletus insects, which were frozen at $-80^{\circ} \mathrm{C}$ without any liquid. They were suspended in a $2 \mathrm{ml}$ Eppendorf tube with $1 \mathrm{ml}$ of PBS containing protease inhibitor 
cocktail according to the manufacturer's specification (Sigma-Aldrich, St. Louis, MO, USA) and crushed with a micropestle. The sample was centrifuged at 14000 $\mathrm{rpm}$ for $10 \mathrm{~min}$ at $4^{\circ} \mathrm{C}$ to remove any insoluble material, the supernatant was filtered through a sterile $0.22 \mu \mathrm{m}$ pore diameter Millex-GV filter (Millipore, Amsterdam, NL) and the protein content of the filtrate was measured at an OD of 280nm with a Nanodrop ND-1000 (Thermo Scientific, Etten-Leur, NL). This WBE was snap-frozen in liquid nitrogen en stored at $-80^{\circ} \mathrm{C}$ (van der Meide et al., 2012).

\subsection{Culicoides-specific serum IgE levels}

According to Van der Meide et al. (2012) a costar 96-well microtiter plate was coated with $100 \mu \mathrm{l}$ per well of $10 \mu \mathrm{g} / \mathrm{ml}$ C. obsoletus WBE in PBS and incubated overnight at $4^{\circ} \mathrm{C}$. The next day, the plate was washed 3 times with $0.05 \%$ Tween20 in PBS and each well was incubated with $150 \mu$ l blocking buffer containing $1.5 \%$ casein (SDT, Baesweiler, Germany) for 1.5 hours at RT. The wells were washed 5 times with $0.05 \%$ Tween 20 in PBS and subsequently incubated with the serum samples diluted $1: 5$ in $1.5 \%$ casein buffer in duplicate. After washing, wells were incubated with $100 \mu \mathrm{l}(2.5 \mu \mathrm{g} / \mathrm{ml})$ mouse monoclonal anti-equine IgE-176 (Wagner et al., 2003) for 1 hour at RT. Again the wells were washed 5 times. Subsequently, wells were incubated for 1 hour at RT with 1:1000 goat anti-mouse IgG peroxidase conjugate (AbD Serotec, Düsseldorf, Germany) in casein buffer. After washing 5 times wells were incubated with $100 \mu$ high sensitivity tetramethylbenzidine (SDT, Baesweiler, Germany) for $10 \mathrm{~min}$ at RT. The reaction was stopped by adding $100 \mu$ of $1 \% \mathrm{HCL}$ per well. Absorbance was measured with a SpectraMax M5 multi-mode microplate reader (Molecular Devices, Berkshire, UK) at a wavelength of $450 \mathrm{~nm}$ corrected for the OD measured at $650 \mathrm{~nm}$. 


\subsection{Histological examination of skin samples}

Paraffin-embedded biopsies were cut in $4 \mu \mathrm{m}$ sections and stained with haematoxylin-eosin (HE) for routine histopathology. A semi-quantitative grading system ( $0=$ absent, $1=$ minimal, $2=$ mild, $3=$ moderate, $4=$ severe $)$ was used to assess the degree of epidermal (both hyperplasia and hyperkeratosis) and dermal (infiltration of both mononuclear cells and eosinophils) changes. The overall histological grade, defined as the sum of the grades for each of these parameters, was determined for each biopsy. All slides were analyzed by the same European College of Veterinary Pathologists-certified pathologist, who was blind with regard to the group and time assignment of biopsies.

\subsection{Quantitative Real-time reverse transcription-polymerase chain reactions}

Frozen skin samples were disrupted and homogenized in TRIzol reagent (Invitrogen, Breda, NL) using a Biopulverizer (Biospec \#59012N, Biospec Inc., Bartlesville, OK) and polytron (PT 1200 E, Kinematica AG, Lucerne, CH). TRIzol manufacturer's instructions were followed until the water-phase was obtained after the chloroform step. Subsequently, total RNA was extracted using RNeasy columns (Qiagen, Venlo, NL) and eluted with $30 \mu$ l of RNase free water. The RNA was quantified spectrophotometrically using a Nanodrop ND-1000 (Thermo Scientific, Etten-Leur, NL). One $\mu \mathrm{g}$ of total RNA was used to produce cDNA with an iScript cDNA Synthesis Kit (Bio-Rad laboratories, Veenendaal, NL) according to manufacturer's instructions. A 5' nuclease assay using TaqMan probes was employed for qRT-PCR amplification. Expression of the following genes was assessed: IL4, IL10, IL13, IFNY, FoxP3 and $\mathrm{CD}_{\zeta}$. Reactions were performed in 25 $\mu \mathrm{l}$ volumes containing $5 \mu \mathrm{l}$ CDNA, $12.5 \mu$ TaqMan Universal PCR Mastermix (Applied Biosystems, Austin, TX, USA), $0.9 \mu \mathrm{M}$ relevant primers and $0.25 \mu \mathrm{M}$ fluorescence-labeled probes and milliQ. The qRT-PCR were performed in an iCycler (Bio-Rad laboratories, Veenendaal, NL) with amplification conditions of 2 $\min$ at $50^{\circ} \mathrm{C}, 10 \mathrm{~min}$ at $95^{\circ} \mathrm{C}$, followed by 45 cycles of $15 \mathrm{~s}$ at $95^{\circ} \mathrm{C}$ and $1 \mathrm{~min}$ 
at 62,60 or $57^{\circ} \mathrm{C}$ (for details see Table 1 ). Each reaction was ran in duplicate and a no-template control was included to exclude contamination of reagents with CDNA on every plate. PCR efficiencies were calculated using a relative standard curve derived from a cDNA pool of equine PBMC stimulated with pokeweed mitogen (Sigma-Aldrich, St. Louis, MO, USA) for $24 \mathrm{~h}$. Relative expression of IL4, IL10, IL13, IFNY, FoxP3 and $\mathrm{CD}_{\zeta}$ was calculated using the Pfaffl method (Pfaffl, 2001 ) using the housekeeping gene 18 s ribosomal RNA (18s rRNA) as a reference gene. To asses the role of T cells in IBH the ratios of IL4, IL10, IL13, IFNY, FoxP3 with $\mathrm{CD}_{\zeta}$ were determined.

\subsection{Statistical analyses}

Statistical analyses were carried using GraphPad Prism 4.00 (Graphpad Software, San Diego, CA). As our data were not normally distributed, correlation between $C$. obsoletus-specific IgE levels and total LE skin histological scores was examined using a non-parametric correlation (Spearman) test. The MannWhitney $U$ test $(+)$ was used to compare values from $\mathrm{IBH}$-affected ponies with those from healthy controls. The non-parametric paired Wilcoxon Signed-Rank Test (WSR Test) $\left(^{*}\right)$ was used for comparison of paired data (lesional/non-lesional and IBH season/off season). Results were considered significant at $p \leq 0.05$.

\section{Results}

\subsection{C. obsoletes-specific IgE levels}

C. obsoletus-specific IgE serum levels of ponies with IBH were significantly higher than those in control ponies in both seasons $(P=0.0001$ and $P=0.0002$, respectively) (Fig $1 \mathrm{~A}$ ). However, within each group there was no significant difference between the levels in the IBH season and off season (IBH vs IBH $\mathrm{P}=0.2676$ and Co Vs Co $\mathrm{P}=0.0537)$. 


\subsection{Histopathology}

HE-stained sections of 14 control ponies (Co) and non-lesional skin (NL) of 16 IBH ponies, sampled off season, were examined by light microscopy according to the semi-quantitative grading system. Since some of the ponies were sold during the summer and one died of an unrelated cause, 11 of the control and $15 \mathrm{IBH}-$ affected ponies were available for examination during the IBH season. Control skin histology scores did not differ between the seasons, nor did control skin and NL skin (Tables 2 and 3). The average total histological score was significantly higher $(P=0.0039)$ in LE skin compared to NL skin from the same ponies as well as compared to that of the control animals $(P=0.0006)$ (Fig. $1 B$ and $D)$. More specifically, LE skin had higher numbers of infiltrating mononuclear cells and eosinophils (Tables 2 and 3). In addition, acanthosis and hyperkeratosis were found only in LE skin.

The total histological scores of LE skin of the IBH ponies did not correlate with their Culicoides-specific IgE values ( $P=0.4366)$ (Fig. 1C).

\subsection{Cytokine expression levels in the skin}

The mRNA expression levels of $\mathrm{CD}_{\zeta}$, a marker for $\mathrm{T}$ cells, normalized against $18 \mathrm{~s}(\mathrm{CD} 3 / 18 \mathrm{~s})$ were significantly increased in the IBH season in healthy control skin $(P=0.0039)$ compared to off season; the same observation was made in NL skin of ponies with IBH ( $P=0.0001)$ (Fig. 2). However, there was no difference between NL and LE skin in the IBH season nor between Co and NL skin in the off season (Fig. 2).

The ratio IL4/CD3 ${ }_{\zeta}$, as determined by IL4/18s divided by its corresponding $\mathrm{CD}_{3} / 18 \mathrm{~s}$ value, both in control and affected ponies showed no difference between seasons (Fig. 3). There was also no difference between Co and NL skin in the off season and Co, NL and LE skin in the IBH season. When comparing only 
IL4/18s expression an increase was observed when comparing NL skin as well as control skin off season and during the IBH season (respectively $\mathrm{P}=0.004$ and $\mathrm{P}=0.0273$ ). In the IBH season no difference was found between healthy, NL and LE skin (supp. Fig. 1).

IL13 mRNA expression off season was not detectable, whereas in the IBH season IL13/CD 3 was lower in LE skin compared to healthy control skin $(P=0.0239)$, but not compared to NL skin (Fig. 4). The same results were obtained when only $18 \mathrm{~s}$ was used for normalization (supp. Fig. 2).

The IFNY/CD3 ${ }_{\zeta}$ analysis showed a significant increase when comparing Co off season and Co IBH season $(P=0.002)$, NL off season versus NL IBH season $(P=0.0002)$. However, there was no difference between Co and NL skin in the off season and Co, NL and LE skin in the IBH season (Fig. 5). The same results were observed when IFNy/18s levels were compared (supp. Fig. 3).

IL10/CD $3_{\zeta}$ mRNA expression levels did not differ between off season and the IBH season (Fig. 6). Moreover, there was no difference between Co and NL skin in the off season and Co, NL and LE skin in the IBH season. Analysis of IL10/18s shows a tendency for increased IL10 expression in the IBH season (supp. Fig. 4).

Analysis of FoxP3/CD3 ${ }_{\zeta}$ mRNA expression showed a significant down regulation between Co off season and Co skin in the IBH season $(P=0.0078)$ (Fig. 7). However, there was no difference between NL off season and NL skin in the IBH season. The same was observed for NL and LE skin in the IBH season. Finally, there was no difference in FoxP3 expression levels between on and off season normalized against only $18 \mathrm{~s}$. There was also no difference between Co and NL skin in the off season and Co, NL and LE skin in the IBH season (supp. Fig. 5).

\section{Discussion}

IBH is an IgE-mediated, pruritic skin disorder caused primarily by Culicoides spp. Differences in cell types present in the skin and as a potential consequence 
in functional immunological aspects between IBH "on and off" season may be indicative for processes underlying the disease. In general, IBH is thought to be a Type-1 hypersensitivity with a potential Th2 skewed immune responsiveness (Hamza et al., 2007, Heimann et al., 2011).

In the present study, we examined the skin-infiltrating cells by histopathological analysis as well as cytokine expression by PCR in the off and IBH season in the same pony to determine Th1 versus Th2 immune responsiveness. Additionally, specific IgE serum levels were measured to determine correlation between allergen-specific IgE levels and the presence of histological manifestations.

A study by Wagner et al. (2006) provided the first direct evidence that IgE mediates classical Type-I hypersensitivity in horses and plays a major role in the pathogenesis of IBH. In addition, C. nubeculosus-specific IgE serum levels were found in IBH-affected horses (Heimann et al., 2011). Such a finding is comparable with the situation in other animals such as the dog, where significantly higher flea-specific IgE levels where found in cases of flea allergy dermatitis (FAD) than in healthy dogs (Halliwell and Longino, 1985, McKeon and Opdebeeck, 1994).

The C. obsoletus WBE-specific IgE titers in IBH ponies are higher than those in the control ponies in the off season as well as in the IBH season, suggesting that in IBH there is a Th2 skewing of the immune system. There was no difference between the specific IgE serum titers off season and in the IBH season within each group. IgE titers being stable throughout the year indicate continuous production of IgE by plasma cells, which instead of memory B cells do not need to be reactivated to produce $\mathrm{IgE}$.

Next to clinical symptoms, there are currently two major tests to diagnose IBH in ponies and horses i) the intradermal skin test using WBE, ii) a culicoidesspecific serum IgE ELISA. The intradermal skin allergy test is based on degranulation of mast cells in vivo, causing tissue swelling, due to cross-linking of 
Culicoides-specific IgE by the allergen and the ELISA assay is based on the binding of Culicoides specific serum IgE to Culicoides extract coated plates. Since Culicoides-specific IgE is the most important factor in both these tests and IgE titers seem to stay stable between seasons it is likely that these tests can be done off season as well as in the IBH season.

The higher histological scores for LE skin suggests a Th2 response of the immune system. There was however, no difference between healthy control skin and NL skin of IBH ponies in the IBH season. This might be explained by the fact that only mild clinical symptoms were found in all IBH ponies potentially due to the relatively cold IBH season, and consequently less active C. obsoletus midges than in an average season.

Remarkably, there was no correlation between the allergen specific IgE titer and the total histological score of LE skin from the same pony. This indicates that levels of free serum IgE can not be used as markers for the severity of IBH. An explanation for the discrepancy may be that circulating allergen-specific IgE levels do not reflect the amount of mast cell- or eosinophil-bound IgE, which more likely contributes to the inflammatory response. In addition, Wagner et al. (2006) suggest that IgG(T), which can also activate skin mast cells, may play a role in IBH (Wagner et al., 2006). Also in dogs with FAD, flea-specific IgG levels are higher than in healthy dogs (Halliwell and Longino, 1985).

To further assess our hypothesis that a mixed Th2/Th1-type immune status, off season, alters to a Th2-dominated immune response in the skin of IBH-affected ponies, hence local immune response parameters, skin mRNA expression levels of IL4, IL10, IL13, $\mathrm{CD}_{\zeta}$, FoxP3 and IFNy were determined.

The $\mathrm{CD}_{\zeta}$ mRNA expression in skin of IBH-affected and control ponies was determined to assess differential $\mathrm{T}$ cells presence. A significant increase in T cells was observed in Co skin in the IBH season as compared to off season. The same was seen in NL skin. However, there was no significant difference between Co and NL skin in the off season, nor in all types of skin in the IBH season, which 
suggests that the immune system in the skin is activated. This activation might be due to other seasonal factors such as bites of mosquitoes and warble flies. It might even be preferential to perform experiments during the off season to exclude additional effects from other insect bites, which might interfere with the assays.

To address Th2 skewing of the immune response in IBH, we examined mRNA expression of the Th1 type cytokine IFNy and of the Th2 type cytokines IL4 and IL13. These mRNA levels were subsequently assessed relative to the corresponding $\mathrm{CD}_{\zeta}$ mRNA levels since these cytokines are mainly secreted by $\mathrm{T}$ cells. There was no difference between NL and LE skin in the IBH season in expression of IL4, which was increased in the IBH season in both controls and ponies with IBH when only normalised with $18 \mathrm{~s}$ (sup. Fig.1). Correcting for the number of T cells (IL4/CD3 $3_{\zeta}$ ) abolished the significant increase of IL4 in Co and IBH skin (Fig. 2). This indicates that the increase in IL4 mRNA expression is due to increased numbers of T cells, which is in line with the study of Heimann et al (2011) where difference in IL4/18s expression between healthy horses and horses with IBH were observed neither. Similar observations have been reported for example in healthy dogs and dogs with FAD (Wuersch et al., 2006). The lack of altered IL4 expression by T cells and the general increase of IL4/18s suggests that other factors may contribute to the development of clinical manifestations.

In the present study, a substantial expression of IL13 mRNA was observed during the IBH season suggesting again a general immune activation in all types of skin. In the IBH season a significant lower expression of IL13/CD3 $\zeta$ was observed in chronic lesional skin as compared to control skin. IL13 as a Th2 cytokine plays a role in the effector phase of allergic reactions (Corry, 1999). Hence, IL13 mRNA levels are expected to increase in acute lesional skin as shown by Heimann et al (2011), but maybe not in chronic lesional skin, which was confirmed by our results. A similar situation has been described for FAD dogs (Wuersch et al., 2006). A down regulation of IL13 was observed after in vitro 
stimulation of allergic skin exposed to fleas for 4 days with flea antigen (Wuersch et al., 2006) which is coherent with our observation in vivo. Hence, T cells do not seem to alter IL13 production in our study. However, we do need to take into account that chronic lesional skin was examined and that Heimann et al. (2011) did find a significant increase in IL13 in more acute lesional skin indicating a Th2 skewing of the immune response.

Our study showed an overall significant elevation of IFNy in the IBH season as compared to off season confirming a general activation of the immune system in the skin. Contrary to elevated IFNy levels in human chronic AD lesions (Grewe et al., 1995), there were no differences observed in IFNY mRNA expression between control, non-lesional and chronic lesional skin of ponies in the IBH season (Fig. 5), which is in line with earlier reports by Heimann et al. (2011). Our combined results indicated a mixed Th2/Th1 cytokine expression in both seasons, but at a higher level during the IBH season.

In addition, to the Th1 and Th2 cytokines, Treg cells have been suggested to play a major role in allergies in humans (Palomares et al., 2010). We therefore decided to examine FoxP3 and IL10 mRNA expression. FoxP3 expression relative to that of $\mathrm{CD}_{\zeta}$ only showed a significant decrease in healthy skin in IBH season compared to the off season. This suggests that there is a decrease of Treg cells in the skin of healthy ponies in the IBH season. This yet remains to be explained. There was no difference in FoxP3 expression between healthy and NL skin off season. Furthermore, there was no difference between healthy, NL and LE skin in the IBH season (Fig. 7). When examining the FoxP3/18s data no significant differences could be found. This suggests that numbers of FoxP3 positive cells in the skin do not differ between healthy and IBH-affected ponies. This is in contrast with the study of Heimann et al (2011), which reported a significant decrease in FoxP3 in NL and LE skin compared to healthy skin suggesting a decrease in Tregs. The reason for these differences might be that they have omitted horses with low histological scores from further analysis. In line with our results a study by 
Hamza et al (2012) showed that the number of $\mathrm{CD} 4^{+} \mathrm{CD}^{2} 5^{\text {thi }} \mathrm{FoxP}^{+} \mathrm{T}$ cells levels in PBMC of healthy horses was similar to that in IBH-affected horses. In addition, when $\mathrm{CD}^{+}{ }^{+} \mathrm{CD} 25^{+} \mathrm{T}$ cells were stimulated with $\mathrm{C}$. nubeculosus extract, expression of FoxP3 was significantly higher in healthy controls compared to IBHaffected horses (Hamza et al., 2012). Our results do not address the reactivity of Treg cells in the skin of IBH-affected ponies compared to healthy ponies.

There was no difference in IL10/CD3 $\zeta$ between seasons. Moreover, there was also no difference between control, non-lesional and chronic lesional skin in the IBH season (Fig. 6), which is similar to the observations of Heimann et al (2011). Our current approach does not confirm a regulatory role for IL10, a longitudinal study may give more inside into the kinetics.

In summary, our data of the same ponies in the off season versus the IBH season showed a general increase of $\mathrm{CD}_{\zeta}$ expression in the IBH season. IL4/18s, IL13 and IFNy levels were also higher in the IBH season compared to the off season. The increased level of C. obsoletus-specific IgE and number's of cutaneous eosinophils, although not correlated in LE skin, both suggest a Th2 type reactivity of the immune system of IBH-affected ponies. However, based on the IL4, IL13 and IFNy parameters the Th2/Th1 balance seems to be maintained. Moreover, the role of regulatory T cells (FoxP3 and IL10) could not be confirmed in the present study. These overall results suggest that the immune system in the skin for healthy and IBH-affected ponies is activated in the IBH season in general. Our data warrant a careful re-evaluation of studies describing the immune status of the skin, taking general seasonal influences in account.

\section{Conflict of interest}

The authors declare no conflict of interest. 


\section{Acknowledgments}

The authors want to thank all Shetland pony owners for their cooperation and

P.W.T. Stolk (Stolk Equine Consultancy, Leersum, The Netherlands) for some of the clinical procedures performed in this study. We are grateful to Eliane Marti (Vetsuisse Faculty, University of Bern, Switserland) for providing an IL13-positive cDNA control sample for our QPCR assay. We would also like to thank Anouk Schurink (Animal Breeding and Genomics Centre at Wageningen University, The Netherlands) for providing a list of potential participants for our study.

This work is financially supported by the Dutch Technology Foundation (STWNWO, Utrecht, The Netherlands), the Dutch Federation of horse breeding ('sHertogenbosch, The Netherlands) and ALK-Abelló/Artu Biologicals (Almere, The Netherlands).

\section{References}

Ainsworth, D.M., Appleton, J.A., Eicker, S.W., Luce, R., Julia Flaminio, M., Antczak, D.F., 2003. The effect of strenuous exercise on mRNA concentrations of interleukin-12, interferon-gamma and interleukin-4 in equine pulmonary and peripheral blood mononuclear cells. Vet. Immunol. Immunopathol. 91, 61-71.

Ander, M., Meiswinkel, R., Chirico, J., 2012. Seasonal dynamics of biting midges (Diptera: Ceratopogonidae: Culicoides), the potential vectors of bluetongue virus, in Sweden. Vet. Parasitol. 184, 59-67.

Ander, M., Meiswinkel, R., Chirico, J., 2012. Seasonal dynamics of biting midges (Diptera: Ceratopogonidae: Culicoides), the potential vectors of bluetongue virus, in Sweden. Vet. Parasitol. 184, 59-67.

Anderson, G.S., Belton, P., Kleider, N., 1988. The hypersensitivity of horses to Culicoides bites in British-Columbia. Can. Vet. J. -Rev. Vet. Can. 29, 718-723.

Corry, D.B., 1999. IL-13 in allergy: home at last. Curr. Opin. Immunol. 11, 610614.

de Raat, I.J., van den Boom, R., van Poppel, M., Sloet van OldruitenborghOosterbaan, M.M., 2008. The effect of a topical insecticide containing permethrin on the number of Culicoides midges caught near horses with and without insect bite hypersensitivity in the Netherlands. Tijdschr. Diergeneeskd. 133, 838-842.

Debrue, M., Hamilton, E., Joubert, P., Lajoie-Kadoch, S., Lavoie, J., 2005. Chronic exacerbation of equine heaves is associated with an increased expression of 
interleukin-17 mRNA in bronchoalveolar lavage cells. Vet. Immunol. Immunopathol. 105, 25-31.

Ferroglio, E., Pregel, P., Accossato, A., Taricco, I., Bollo, E., Rossi, L., Trisciuoglio, A., 2006. Equine Culicoides hypersensitivity: evaluation of a skin test and of humoral response. J. Vet. Med. A Physiol. Pathol. Clin. Med. 53, 30-33.

Grewe, M., Walther, S., Gyufko, K., Czech, W., Schopf, E., Krutmann, J., 1995. Analysis of the Cytokine Pattern Expressed In Situ in Inhalant Allergen Patch Test Reactions of Atopic Dermatitis Patients. J Investig Dermatol 105, 407-410.

Halliwell, R.E.W., Longino, S.J., 1985. IgE and IgG antibodies to flea antigen in differing dog populations. Vet. Immunol. Immunopathol. 8, 215-223.

Hamza, E., Doherr, M.G., Bertoni, G., Jungi, T.W., Marti, E., 2007. Modulation of Allergy Incidence in Icelandic Horses Is Associated with a Change in IL-4Producing T Cells. International Archives of Allergy and Immunology 144, 325337.

Hamza, E., Steinbach, F., Marti, E., 2012. CD4(+)CD25(+) T cells expressing FoxP3 in Icelandic horses affected with insect bite hypersensitivity. Vet. Immunol. Immunopathol. 148, 139-144.

Hamza, E., Torsteinsdottir, S., Eydal, M., Frey, C.F., Mirkovitch, J., Brcic, M., Wagner, B., Wilson, A.D., Jungi, T.W., Marti, E., 2010. Increased IL-4 and decreased regulatory cytokine production following relocation of Icelandic horses from a high to low endoparasite environment. Vet. Immunol. Immunopathol. 133, 40-50.

Hamza, E., Wagner, B., Jungi, T.W., Mirkovitch, J., Marti, E., 2008. Reduced incidence of insect-bite hypersensitivity in Icelandic horses is associated with a down-regulation of interleukin- 4 by interleukin-10 and transforming growth factor- $\beta 1$. Vet. Immunol. Immunopathol. 122, 65-75.

Heimann, M., Janda, J., Sigurdardottir, O.G., Svansson, V., Klukowska, J., von Tscharner, C., Doherr, M., Broström, H., Andersson, L.S., Einarsson, S., Marti, E., Torsteinsdottir, S., 2011. Skin-infiltrating T cells and cytokine expression in Icelandic horses affected with insect bite hypersensitivity: A possible role for regulatory $T$ cells. Vet. Immunol. Immunopathol. 140, 63-74.

Hellberg, W., Wilson, A.D., Mellor, P., Doherr, M.G., Torsteinsdottir, S., Zurbriggen, A., Jungi, T., Marti, E., 2006. Equine insect bite hypersensitivity: Immunoblot analysis of IgE and IgG subclass responses to Culicoides nubeculosus salivary gland extract. Vet. Immunol. Immunopathol. 113, 99-112.

Kolm, G., Knapp, E., Wagner, R., Klein, D., 2007. Lactoferrin, a glycoprotein with immunomodulatory and mast cell stabilising properties, in skin of horses suffering from Culicoides hypersensitivity. Res. Vet. Sci. 83, 165-170.

Kurotaki, T., Narayama, K., Oyamada, T., Yoshikawa, H., Yoshikawa, T., 1994. Immunopathological study on equine insect hypersensitivity ("kasen") in Japan. J. Comp. Pathol. 110, 145-152. 
McKelvie, J., Foster, A.P., Cunningham, F.M., Hamblin, A.S., 1999.

Characterisation of lymphocyte subpopulations in the skin and circulation of horses with sweet itch (Culicoides hypersensitivity). Equine Vet. J. 31, 466-472.

McKeon, S.E., Opdebeeck, J.P., 1994. IgG and IgE antibodies against antigens of the cat flea, Ctenocephalides felis felis, in sera of allergic and non-allergic dogs. Int. J. Parasitol. 24, 259-263.

Palomares, O., Yaman, G., Azkur, A.K., Akkoc, T., Akdis, M., Akdis, C.A., 2010. Role of Treg in immune regulation of allergic diseases. Eur. J. Immunol. 40, 1232-1240.

Pfaffl, M.W., 2001. A new mathematical model for relative quantification in realtime RT-PCR. Nucleic Acids Research 29, 45.

Scott, D.W., 1990. Histopathologie cutanée de I'hypersensibilité aux piqures de Culicoides chez le cheval. Point Vét. 22, 583-588.

Sloet van Oldruitenborgh-Oosterbaan, M.M., van Poppel, M., de Raat, I.J., van den Boom, R., Savelkoul, H.F.J., 2008. Intradermal testing of horses with and without insect bite hypersensitivity in the Netherlands using an extract of native Culicoides species. Veterinary dermatology 20,607-614.

Steinman, A., Peer, G., Klement, E., 2003. Epidemiological study of Culicoides hypersensitivity in horses in Israel. Vet. Rec. 152, 748-751.

Swiderski, C.E., Klei, T.R., Horohov, D.W., 1999. Quantitative measurement of equine cytokine mRNA expression by polymerase chain reaction using targetspecific standard curves. J. Immunol. Methods 222, 155-169.

van den Boom, R., Ducro, B., Sloet van Oldruitenborgh-Oosterbaan, M.M., 2008. Identification of factors associated with the development of insect bite hypersensitivity in horses in The Netherlands. Tijdschr. Diergeneeskd. 133, 5549.

van der Meide, N.M.A., Meulenbroeks, C., van Altena, C., Schurink, A., Ducroc, B., Wagner, B., Leibolde, W., Rohwere, J., Jacobs, F., Sloet van OldruitenborghOosterbaan, M.M., Savelkoul, H., Tijhaar, E.F.J., 2012. Culicoides obsoletus extract relevant for diagnostics of insect bite hypersensitivity in horses in The Netherlands. Vet. Immunol. and Immunopathol., Vet. Immunol. Immunopathol. $149,245-254$.

van der Rijt, R., van den Boom, R., Jongema, Y., van Oldruitenborgh-Oosterbaan, M.M., 2007. Culicoides species attracted to horses with and without insect hypersensitivity. Vet. J. 178, 91-97.

Van Grevenhof, E.M., Ducro, B., Heuven, H.C.M., Bijma, P., 2007. Identification of environmental factors affecting the prevalence of insect bite hypersensitivity in Shetland ponies and Friesian horses in the Netherlands. Equine Vet. J. 39, 69-73.

Wagner, B., Miller, W.H., Morgan, E.E., Hillegas, J.M., Erb, H.N., Leibold, W., Antczak, D.F., 2006. IgE and IgG antibodies in skin allergy of the horse. Vet. Res. $37,813-825$. 
Wagner, B., Radbruch, A., Rohwer, J., Leibold, W., 2003. Monoclonal anti-equine IgE antibodies with specificity for different epitopes on the immunoglobulin heavy chain of native IgE. Veterinary Immunology and Immunopathology 92, 45-60.

Wilson, A.D., Harwood, L.J., Bjornsdottir, S., Marti, E., Day, M.J., 2001. Detection of IgG and IgE serum antibodies to Culicoides salivary gland antigens in horses with insect dermal hypersensitivity (sweet itch). Equine Vet. J. 33, 707-713.

Wuersch, K., Brachelente, C., Doherr, M., Reist, M., Sattler, U., Forster, U., Bertoni, G., Peel, J.E., Welle, M., 2006. Immune dysregulation in flea allergy dermatitis-A model for the immunopathogenesis of allergic dermatitis. Vet. Immunol. Immunopathol. 110, 311-323. 


\section{Figure captions}

\section{Fig1.}

C. obsoletus-specific IgE serum levels and histology in the off season and in the IBH season. IgE serum levels and histological scores of skin of 14 control and 16 IBH ponies (off season) and 11 control and 15 IBH ponies (IBH season) were examined. Histology scores of lesional skin of 9/15 IBH ponies were determined. (A) C. obsoletus-specific IgE serum levels as determined by ELISA assay. The bars represent the mean of all samples in the group. (B) Mean histological scores were determined according to a semi-quantitative grading system (0-4) for acanthosis, hyperkeratosis, lymphocyte infiltration and eosinophilic granulocytes (C) C. obsoletus-specific IgE serum levels plotted against the lesional skin's total histological sores ( $P=0.4366)$. (D) Representative examples of HE stained section of: a) Off season control skin with few perivascular mononuclear cells in the superficial dermis (average total histological grade 3). b) Off season non-lesional (NL) skin with mild perivascular inflammation (average total histological grade 3). c) IBH season control skin (Co) with minimal perivascular inflammation of the superficial dermis (average total histological grade 3). d) IBH season non-lesional skin (NL) with mild perivascular inflammation (average total histological grade 3 ). e) IBH season non-lesional skin (NL) with pronounced dermal inflammation and moderate numbers of eosinophils (arrow) (average total histological grade 14). Original magnification $400 x$. The bar corresponds to $50 \mu \mathrm{m}$.

\section{Fig 2.}

Expression of $\mathrm{CD}_{\zeta}$ mRNA, a T cell receptor marker. Off season 13 control and 14 IBH ponies were used. In the IBH season 11 of the 13 control ponies were examined and all 14 IBH ponies were examined of which 13 had lesional skin 1 IBH ponies was added in the course of the experiment. The mRNA expression of $\mathrm{CD}_{\zeta}$ was determined with $\mathrm{qRT}-\mathrm{PCR}$ and normalized against the housekeeping 
gene 18s using the Pfaffl method (Pfaffl, 2001). The bars represent the mean of all samples in the group.

\section{Fig 3.}

Expression of IL4/CD3 ${ }_{\zeta}$ mRNA, a Th 2 cytokine. The skin of 13 control and 13 IBH ponies were used during off season. In the IBH season 11 of the 13 control ponies were examined and all 13 plus 2 extra IBH ponies were examined of which 13 had lesional skin. The mRNA expression of IL4 was determined with qRT-PCR and normalized against the housekeeping gene 18s using the Pfaffl method (Pfaffl, 2001) and subsequently divided by the $\mathrm{CD}_{3} / 18 \mathrm{~s}$ value of the same sample. The bars represent the mean of all samples in the group.

\section{Fig 4.}

Expression of IL13/CD3 ${ }_{\zeta}$ mRNA, a Th 2 cytokine. The skin of 13 control and 13 IBH ponies were used during off season. In the IBH season 11 of the 13 control ponies were examined and all 13 plus 2 extra IBH ponies were examined of which 13 had lesional skin. The mRNA expression of IL13 was determined with qRT-PCR and normalized against the housekeeping gene 18s using the Pfaffl method (Pfaffl, 2001) and subsequently divided by the $C D 3 / 18$ s value of the same sample. The bars represent the mean of all samples in the group.

\section{Fig 5.}

Expression of IFNy/CD3 3 mRNA, a Th 1 cytokine. The skin of 10 control and 13 IBH ponies were used during off season. In the IBH season all 10 control ponies plus 1 extra were examined and all 13 plus 2 extra IBH ponies were examined of which 13 had lesional skin. The mRNA expression of IFNy was determined with qRT-PCR and normalized against the housekeeping gene 18s using the Pfaffl method (Pfaffl, 2001) and subsequently divided by the $\mathrm{CD}_{3} / 18 \mathrm{~s}$ value of the same sample. The bars represent the mean of all samples in the group. 


\section{Fig 6.}

Expression of $\mathrm{IL} 10 / \mathrm{CD}_{\zeta} \mathrm{mRNA}$, an immune suppression cytokine. The skin of 11 control and $7 \mathrm{IBH}$ ponies were used during off season. In the IBH season all control ponies were examined and all 7 plus 6 extra IBH ponies were examined, all having lesional skin. The mRNA expression of IL10 was determined with qRTPCR and normalized against the housekeeping gene 18s using the Pfaffl method (Pfaffl, 2001) and subsequently divided by the $C D 3 y / 18$ s value of the same sample. The bars represent the mean of all samples in that group.

\section{Fig 7.}

Expression of FoxP3/CD3 ${ }_{\zeta}$ mRNA, a Treg cell marker. The skin of 11 control and 7 IBH ponies were used during off season. In the IBH season all control ponies were examined and all 7 plus 6 extra IBH ponies were examined, all having lesional skin. The mRNA expression of FoxP3 was determined with qRT-PCR and normalized against the housekeeping gene 18s using the Pfaffl method (Pfaffl, 2001) and subsequently divided by the $C D 3 / 18$ s value of the same sample. The bars represent the mean of all samples in the group.

\section{Supp fig 1.}

Expression of IL4 mRNA, a Th 2 cytokine. The skin of 13 control and 13 IBH ponies were used during off season. In the IBH season 11 of the 13 control ponies were examined and all 13 plus 2 extra IBH ponies were examined of which 13 had lesional skin. The mRNA expression of IL4 was determined with qRT-PCR and normalized against the housekeeping gene 18s using the Pfaffl method (Pfaffl, 2001). The bars represent the mean of all samples in the group. 


\section{Supp fig 2.}

Expression of IL13 mRNA, a Th 2 cytokine. The skin of 13 control and 13 IBH ponies were used during off season. In the IBH season 11 of the 13 control ponies were examined and all 13 plus 2 extra IBH ponies were examined of which 13 had lesional skin. The mRNA expression of IL13 was determined with qRT-PCR and normalized against the housekeeping gene 18s using the Pfaffl method (Pfaffl, 2001). The bars represent the mean of all samples in the group.

\section{Supp fig 3.}

Expression of IFNy mRNA, a Th 1 cytokine. The skin of 10 control and $13 \mathrm{IBH}$ ponies were used during off season. In the IBH season all 10 control ponies plus 1 extra were examined and all 13 plus 2 extra IBH ponies were examined of which 13 had lesional skin. The mRNA expression of IFNy was determined with qRT-PCR and normalized against the housekeeping gene $18 \mathrm{~s}$ using the Pfaffl method (Pfaffl, 2001). The bars represent the mean of all samples in the group.

\section{Supp fig 4.}

Expression of IL10 mRNA, an immune suppression cytokine. The skin of 11 control and $7 \mathrm{IBH}$ ponies were used during off season. In the IBH season all control ponies were examined and all 7 plus 6 extra IBH ponies were examined, all having lesional skin. The mRNA expression of IL10 was determined with qRTPCR and normalized against the housekeeping gene 18s using the Pfaffl method (Pfaffl, 2001). The bars represent the mean of all samples in the group.

\section{Supp fig 5.}

Expression of FoxP3/CD3 ${ }_{\zeta}$ mRNA, a Treg cell marker. The skin of 11 control and 7 IBH ponies were used during off season. In the IBH season all control ponies were examined and all 7 plus 6 extra IBH ponies were examined, all having lesional skin. The mRNA expression of FoxP3 was determined with qRT-PCR and 
normalized against the housekeeping gene 18s using the Pfaffl method (Pfaffl, 2001). The bars represent the mean of all samples in the group. 
Fig. 1
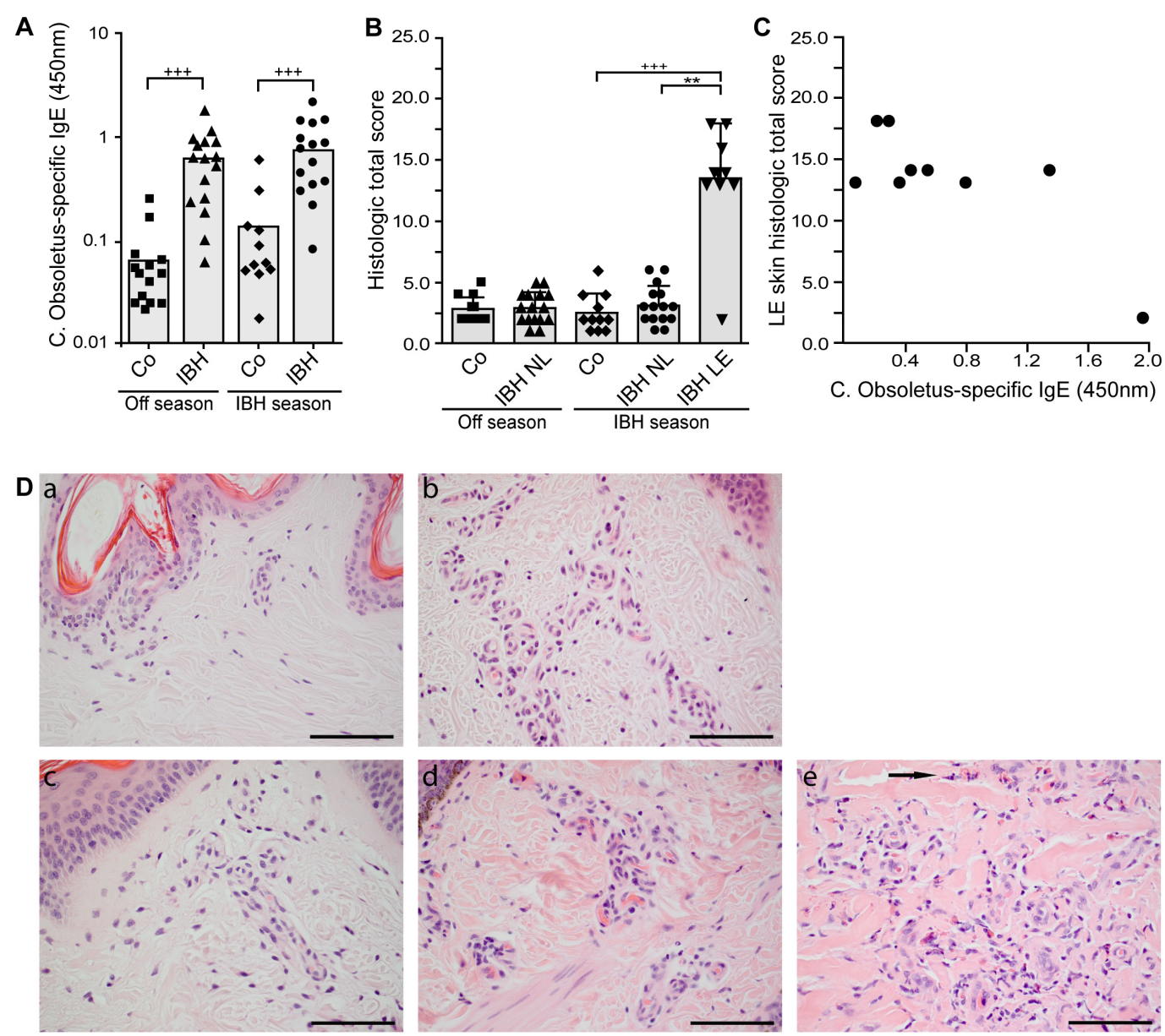

Fig. 2

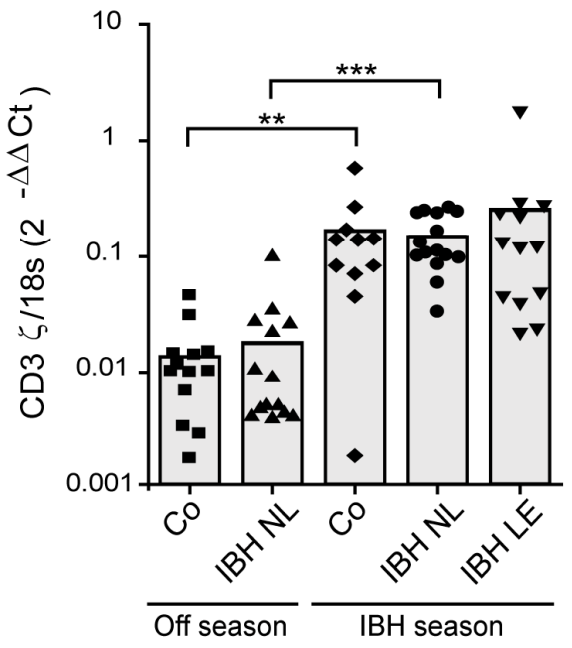


Fig. 3

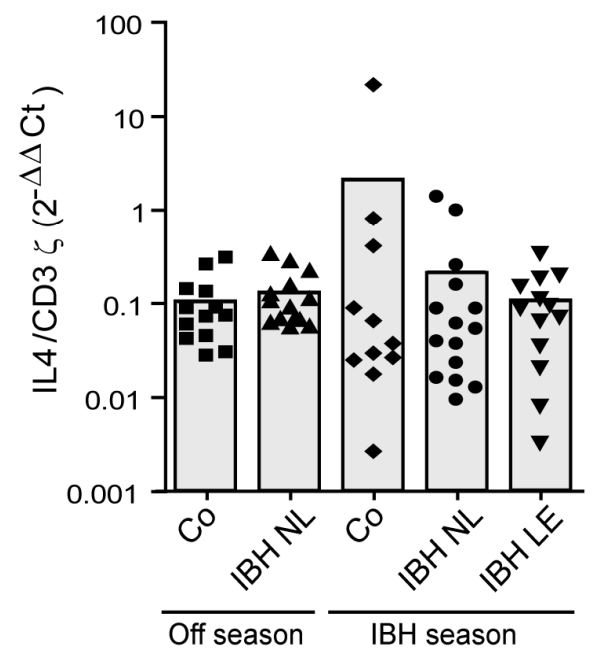

Fig. 4

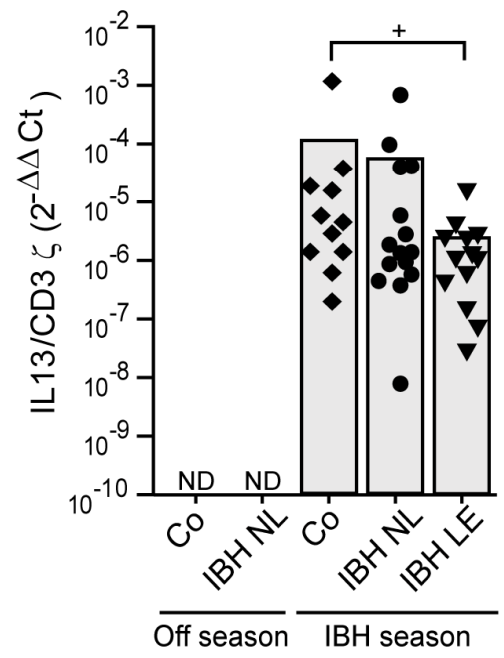


Fig. 5

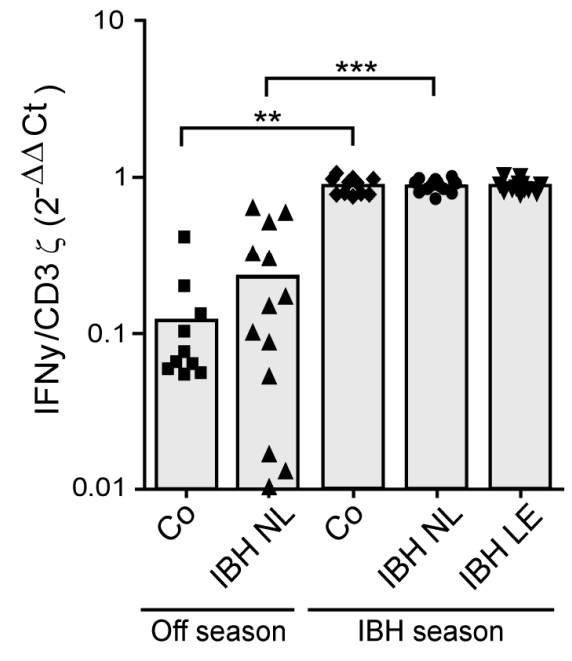

Fig. 6

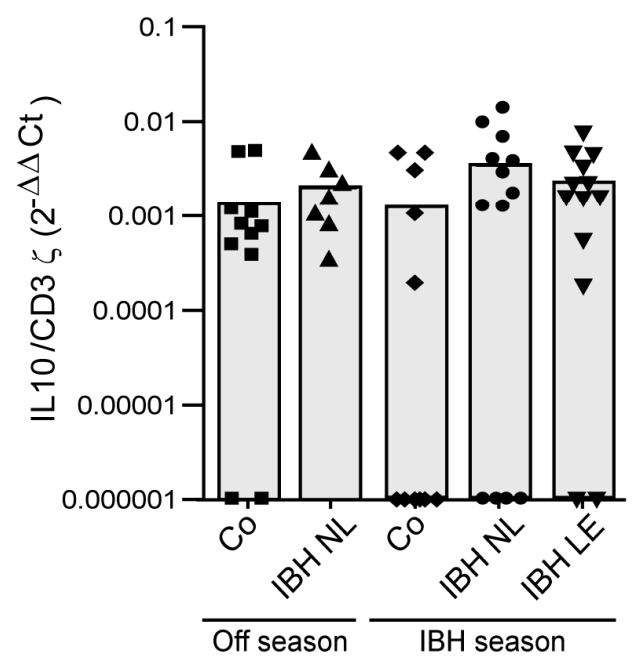


Fig. 7

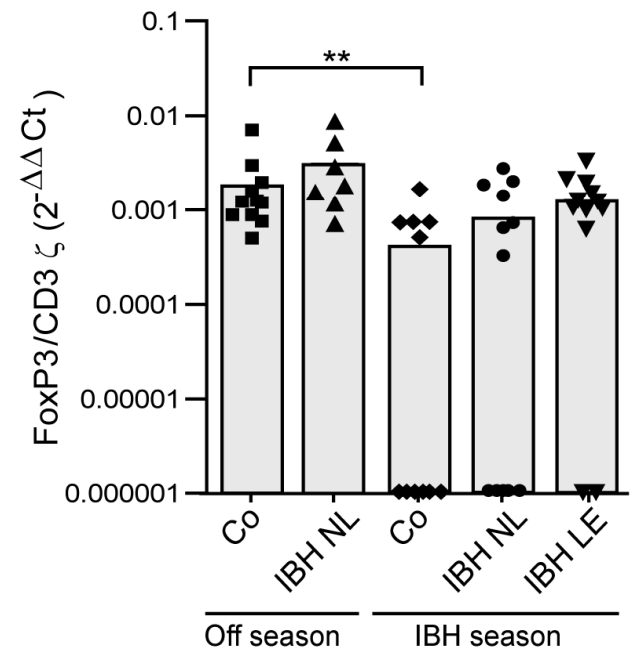


Sup. Fig. 1

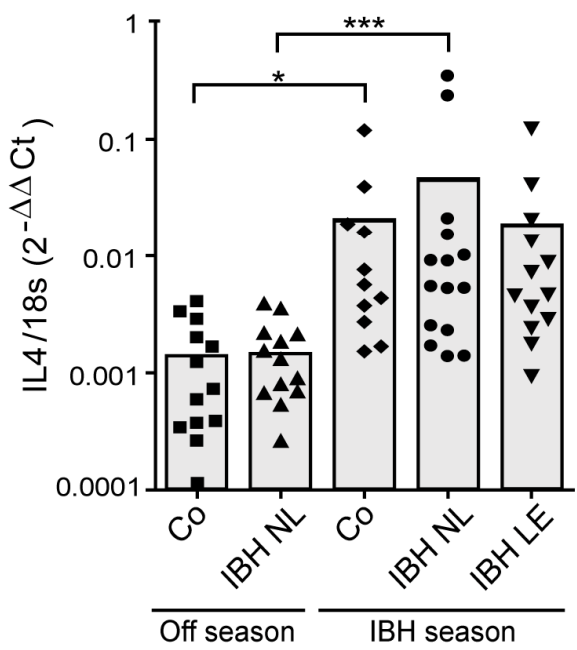

Sup. Fig. 2

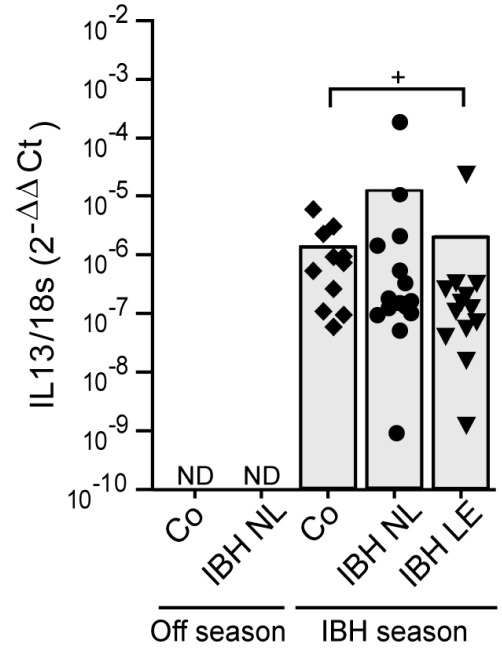


Sup. Fig. 3

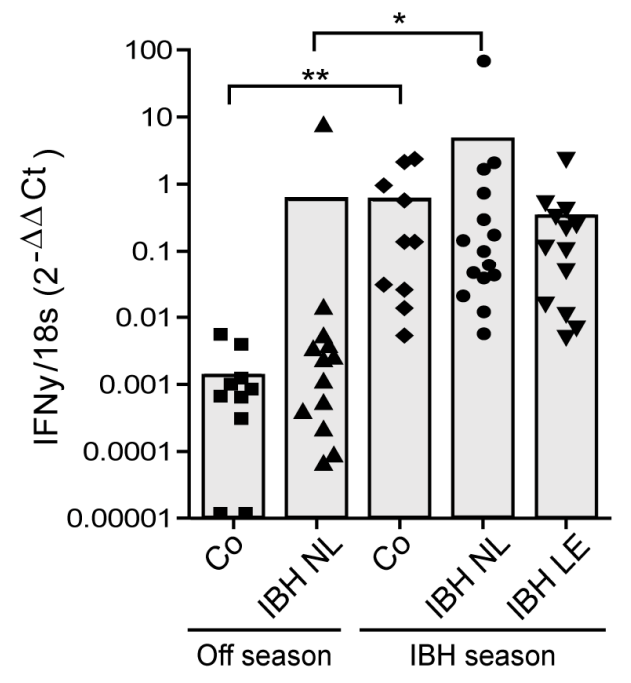

sup Fig. 4

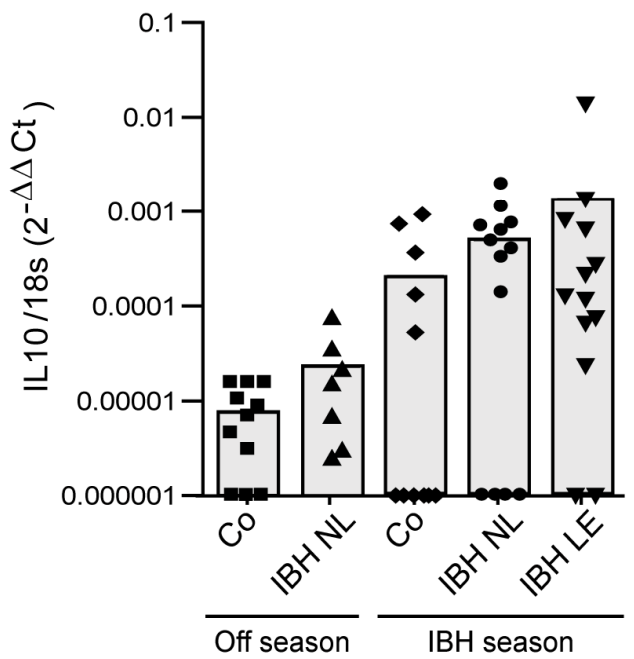


sup Fig. 5

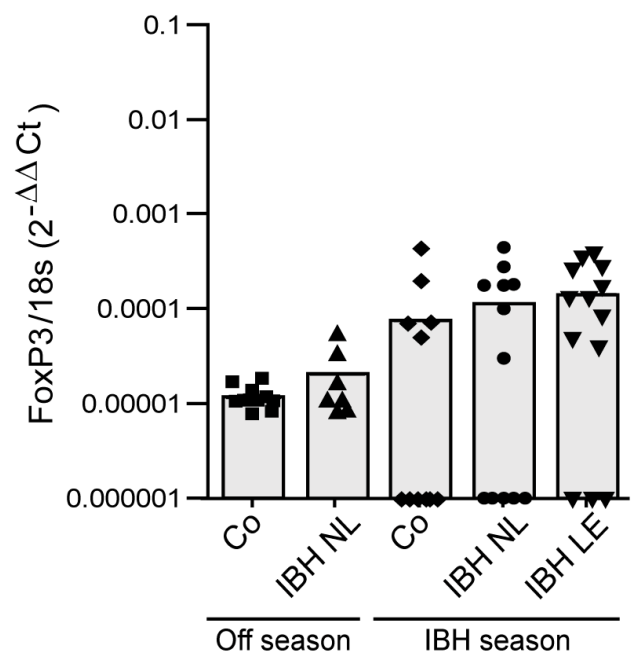




\section{Tables}

Table 1

Primers and probes and the PCR conditions used for qRT-PCR.

\begin{tabular}{|c|c|c|c|c|}
\hline Gene & $\begin{array}{l}\text { CDNA } \\
(\mu \mathrm{l})\end{array}$ & $\begin{array}{c}\mathrm{Ta} \\
\left({ }^{\circ} \mathrm{C}\right) \\
\end{array}$ & reference & Sequences $\left(5^{\prime}-3^{\prime}\right)$ \\
\hline IL4 & 2.5 & 60 & (Ainsworth et al., 2003) & \\
\hline IL10 & 5 & 60 & Primers: (Swiderski et al., 1999) & Probe: 6 FAM-GGCTGAGAACCACGGCCCAG- MGBNFQ \\
\hline IL13 & 2.5 & 60 & (Heimann et al., 2011) & \\
\hline FoxP3 & 2.5 & 59 & NM_001163272.1 & $\begin{array}{l}\text { Forward: CCAGCTATGATCAGCCTTCC } \\
\text { Reverse: GAAGACCTTCTCGCATCCAG } \\
\text { Probe: 6FAM-GCTGGCAAATGGCGTCTGCA- MGBNFQ }\end{array}$ \\
\hline IFNY & 2.5 & 60 & $\begin{array}{l}\text { Ec03468605_g1; Applied } \\
\text { Biosytems }\end{array}$ & \\
\hline $\begin{array}{l}\mathrm{CD}_{\zeta} \\
18 \mathrm{~S}\end{array}$ & $\begin{array}{c}2.5 \\
0.25\end{array}$ & $\begin{array}{l}60 \\
60\end{array}$ & $\begin{array}{l}\text { (Debrue et al., 2005) } \\
\text { 4352930E; Applied Biosytems }\end{array}$ & \\
\hline
\end{tabular}


Table 2

Off season semi-quantitative histological scores (average and range between brackets) from healthy ponies and ponies with IBH.

\begin{tabular}{lcc}
\hline & Healthy $(\mathrm{n}=14)$ & Non-lesional $(\mathrm{n}=16)$ \\
\hline \hline Acanthosis & $0(0-0)$ & $0(0-1)$ \\
Hyperkeratosis & $0(0-1)$ & $0(0-1)$ \\
Upper dermis: lymphocytes & $1(1-2)$ & $1(1-2)$ \\
Upper dermis: eosinophilic granulocytes & $0(0-1)$ & $0(0-1)$ \\
Middle dermis: Iymphocytes & $1(0-2)$ & $1(0-2)$ \\
Middle dermis: eosinophilic granulocytes & $0(0-0)$ & $0(0-1)$ \\
Deep dermis: lymphocytes & $0(0-0)$ & $0(0-0)$ \\
Deep dermis: eosinophilic granulocytes & $0(0-0)$ & $0(0-0)$ \\
\hline Average total histological score & $3(2-5)$ & $3(1-5)$ \\
\hline
\end{tabular}

$0=$ absent, $1=$ minimal, $2=$ mild, $3=$ moderate, $4=$ severe 
Table 3

IBH season semi-quantitative histological scores (average and range between brackets) from healthy ponies and ponies with IBH.

\begin{tabular}{lccc}
\hline IBH season & $\begin{array}{c}\text { Healthy } \\
(\mathrm{n}=11)\end{array}$ & $\begin{array}{c}\text { Non-lesional } \\
(\mathrm{n}=15)\end{array}$ & $\begin{array}{c}\text { Lesional } \\
(\mathrm{n}=10)\end{array}$ \\
\hline \hline Acanthosis & $0(0-0)$ & $0(0-1)$ & $2(1-2)$ \\
Hyperkeratosis & $0(0-0)$ & $0(0-0)$ & $1(0-3)$ \\
Upper dermis: Iymphocytes & $1(1-2)$ & $1(1-2)$ & $2(1-4)$ \\
Upper dermis: eosinophilic granulocytes & $0(0-1)$ & $0(0-1)$ & $1(0-3)$ \\
Middle dermis: lymphocytes & $1(0-2)$ & $1(0-1)$ & $2(0-3)$ \\
Middle dermis: eosinophilic granulocytes & $0(0-1)$ & $0(0-1)$ & $1(0-3)$ \\
Deep dermis: lymphocytes & $0(0-1)$ & $0(0-1)$ & $2(0-3)$ \\
Deep dermis: eosinophilic granulocytes & $0(0-1)$ & $0(0-1)$ & $1(0-2)$ \\
\hline Average total histological score & $3(1-6)$ & $3(1-6)$ & $14(2-18)$ \\
\hline
\end{tabular}

$0=$ absent, $1=$ minimal, $2=$ mild, $3=$ moderate, $4=$ severe 